\title{
A Study on Awareness of Product Placement in Malaysian Movies
}

\author{
Mohd Amir Syafiq Bin Mohd Nordin \& Shahrel Nizar Bin Baharom \\ Faculty Art and Design Universiti Teknologi MARA Perak Branch, Seri Iskandar Campus, \\ 32610 Seri Iskandar, Perak, MALAYSIA. \\ Authors' email: amirrsyaf@gmail.com¹, shahrelnizar@gmail.com²
}

Published: 7 September 2018

\begin{abstract}
Product placement in movies is a strategy to advertise the products and services. This strategy is generally used in international movies and become a trend for Malaysian movies. However, its effectiveness is still questionable especially for the local people. This research aims to discuss about how far the awareness of Malaysian people towards product placement in local movies for the brand recall. By using the qualitative method, the researcher randomly interviewed five participants through in-depth interview. The result shows that most of the participants are aware about the product placement in Malaysian movies and lead to the viewers' brand recall. Therefore, this will give a great potential for advertisers in Malaysia to use the product placement in movies as one of the key strategies for the brand awareness.
\end{abstract}

Keywords: Product Placement, Malaysian Movies, Brand Awareness, Brand Recall

eISSN: 2550-214X (C) 2018. The Authors. Published for Idealogy Journal of Arts and Social Science by UiTM Press. This is an Open Access article distributed under the terms of the Creative Commons Attribution-NonCommercial-NoDerivatives License (http://creativecommons.org/licenses/by-nc-nd/4.0/), which permits non-commercial re-use, distribution, and reproduction in any medium, provided the original work is properly cited, and is not altered, transformed, or built upon in any way.

\section{INTRODUCTION}

Product placement (PP) is a form of advertising and marketing techniques in order to position the brand of products or services in a movie or television program. The use of PP is for the purpose to get instant recognition of the brand image by the viewers. According to Mandal (2008), "Placements can be in form of verbal mentions in dialogue, actual use by character, visual displays such as corporate logos on vehicles or billboards, brands used as set decorations, or even snatches of actual radio or television commercials". According to Balasubramanian (1994), PP has becomes a focus of study for many researchers in advertising field and also in the marketing because PP is not just a new form of advertising but it is a unique position in marketing strategy.

However, the national or cultural differences illustrate dissimilar effect of PP acceptance by the viewers (Gould et.al, 2000). Besides, the individual differences might affect behaviours and attitudes of the viewers toward PP acceptance (Balasubramanian et.al, 2006). This is somehow would influence viewers' brand recall.

Nevertheless, most advertisers or marketers are increasingly using PP especially in movies to reinforce brand awareness and also to create favourable attitudes. Gregorio and Sung (2010) supported that the used of PP in movies is become a common practice around the world and it appears often in blockbuster movies.

In Malaysia, the medium of PP in movies has becomes the interest of most advertisers to advertise their product or services. Therefore, this paper will investigate whether Malaysian people are aware toward PP in movies which might affect their brand recall. 


\section{PRODUCT PLACEMENT FOR BRAND RECALL}

Brand recall is not only about spontaneous recall of consumers toward brand from their memory. It is also related to the advertisers to make a choice between the complete brands being showcased or mention of the brand name. According to Penchmann and Shih (1999), they said that it is depends on the decision whether the memory evaluation can be done for brand recall as propose. Homer (2009) admits that the insufficient evidences regarding PP impact on consumer responses. However, Cowley and Barron (2008) found out that the more consumers are exposed to PP, the more it increases explicit memory for a brand. A telephone survey conducted in 2002 by Morton and Friedman which interviewed several respondents to assess "day-after" recall of feature movies. The results show approximately $38 \%$ of respondents correctly recalled brands appearing in movies that their seen.

Indeed, the result shows that PP is capable to boost the memorizing process. The brand recall of the people improved when PP were visibly with a virtue of size, correct position on the screen or centrality to the action in the scene. Therefore, consumers can recall the features of brands seen in movies spontaneously (Lehu \& Bessoud, 2009). In the context of movies, Cowley and Barron (2008) argued that the brand recall by the viewers in movies does not guarantee an improvement in brand attitude (Cowley and Barron, 2008). They suggested that to emphasis memorization of PP, the advertising strategy should continue with tie-in advertising, endorsement and additional promotion.

Moreover, brand recall can be used as an indicator to measure the effectiveness of a PP (Lehu and Bressoud, 2009). Results of the study conducted by Lehu and Bressoud, (2009), show that only $4.2 \%$ of respondents used spontaneous recall the day after exposure. Besides, Bressoud, Lehu, and Russell (2010), although PP works better in brand recall, brand recognition and brand awareness but somehow it would not lead to purchase intention. Placements in TV show or movie may be too short to make viewers' interest and desire to purchase the product or service.

\section{PRODUCT PLACEMENT FOR BRAND AWARENESS}

Brand awareness is about consumer ability to recognize and recall the brand in different situation (Aaker, 1997). Mandler (1980) depicted that brand awareness is at the lowest end of brand knowledge that parameter starts from the simple brand recognition to the cognitive thinking-based approach which is based on the detail information about the brand. Evidence shows that the main reason for companies to make use of PP in entertainment business is about the brand awareness (Wiles \& Danielova, 2009). If consumers are watching a movie and be so focused on the scene, there is a risk that they do not know and aware of PP. This can cause unconsciously to consumer and PP would not influence them. However, PP could lead to awareness if consumer become aware and able to recognize it and decide themselves if whether or not on their purchase intention (Tessitore and Geuens, 2013).

According to Macdonald and Sharp (2000), brand awareness effects on consumer brand choice and it will bring them to purchase intention, and also can give further impacts on quality consideration toward brand. The study by Janiszewski, Noel, and Sawyer (2003), in which looked into the relationship between advertising repetition and consumer memory revealed that "understanding how different types of repeated ads are received and remembered can provide insight into how to make advertising more real". The repetition of advertisements, along with strategic PP, will form a reminder in the mind of consumers, which will lead to brand awareness (Belch and Belch, 2004).

\section{THE CHALLENGES OF PRODUCT PLACEMENT IN MALAYSIAN MOVIES}

The advertising agencies in Malaysia should endeavour more on PP in local movies. Although the research about the effectiveness of PP in local movies is still modest, it could be an opportunity for advertisers to implement it. However, the effectiveness of PP in Malaysia local movies might reflect to the several issues faced by the Malaysian movies. 
Most of the advertising agencies might not use PP in Malaysian movies because of the low rate of viewers. According to Malaysian Box Office, the National Film Development Corporation (FINAS) claimed only seven local movies that can be categorized as a return on capital with a claim of more than RM1 million while the rest of the Malaysian movies fail. This is indirectly gives a negative impact toward advertisers in Malaysia to use movies as one of their platform for advertising strategy.

On the other hand, The Malaysian Communications and Multimedia Content Code (MCMC) have a stringent rule about PP under The Communication and Multimedia Act 1998. This is including product placements that need to be relevant towards the content of the media shown. Besides, the brands or products which banned in Malaysia are not allowed to be used as PP. Nevertheless, MCMC further added that the joint promotions of different brands showcased in a specific time frame can be permissible. Despite of several challenges, it stills a big chance for advertisers to use PP in local movies.

\section{MALAYSIAN MOVIES THAT USED PRODUCT PLACEMENT}

In this paper, researcher has selected five Malaysian movies that lucratively used PP which mainly promoting five famous brands (Refer Table 1). These five famous brands appear clearly in the scene of the movies for viewers' awareness (Refer Figure 1,2,3,4 and 5).

Table 1: Malaysian movies that used product placement:

\begin{tabular}{llrl}
\hline \multicolumn{1}{c}{ Movies } & Year & \multicolumn{1}{c}{ Brand } \\
$\mathbf{1}$ & Abang Long Fadil 2 & 2017 & Minyak Wakdoyok \\
$\mathbf{2}$ & Ola Bola & 2016 & Milo \\
$\mathbf{3}$ & J-Revolusi & 2016 & U-Mobile \\
$\mathbf{4}$ & Polis Evo & 2015 & Mitsubishi Evo \\
$\mathbf{5}$ & Istanbul Akan Datang & 2012 & Asam Laksa Maggie \\
\hline
\end{tabular}

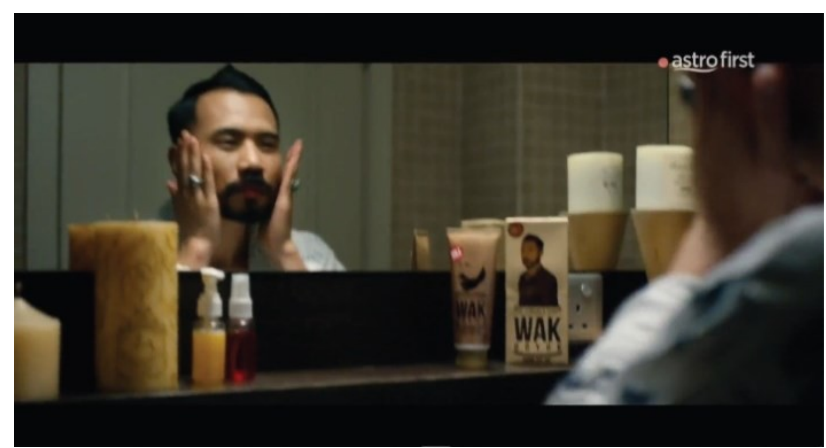

Figure 1: Wakdoyok oil product in Abang Long Fadil 2 Movie

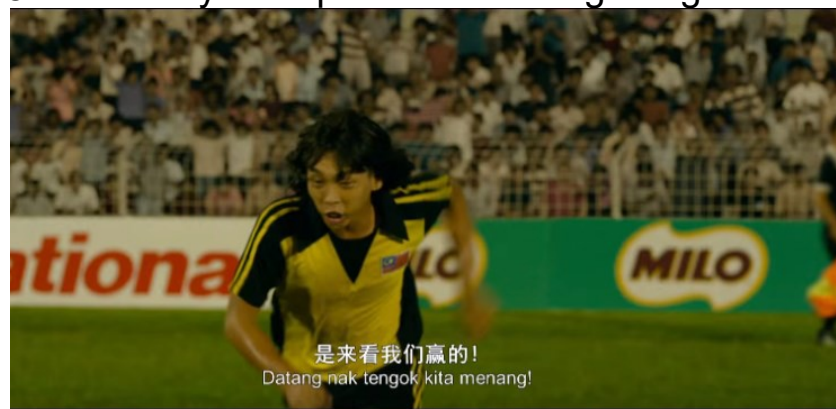

Figure 2: Milo brand in Ola Bola Movie 


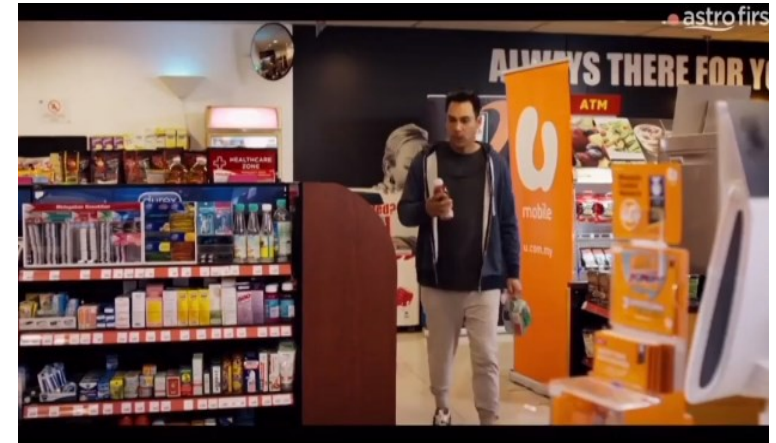

Figure 3: U-Mobile product in J-Revolusi Movie

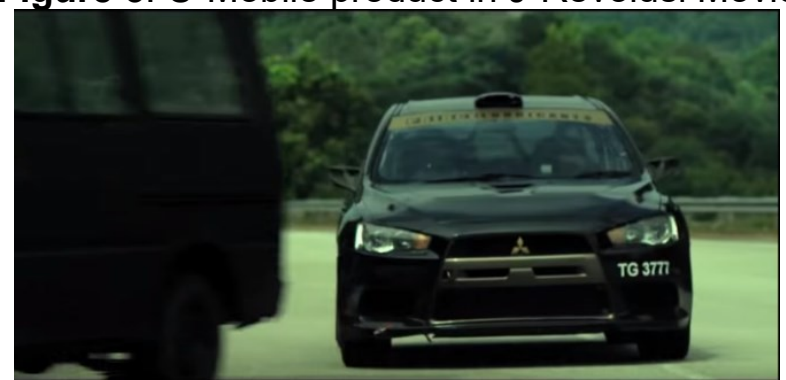

Figure 4: Mitsubishi Evo Car in Polis Evo Movie

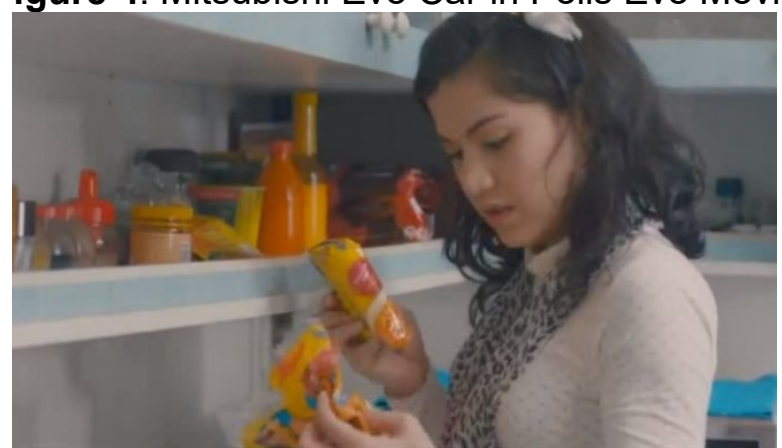

Figure 5: Maggi Asam Laksa product in Istanbul Aku Datang Movie

\section{METHODOLOGY}

The method used in this research is qualitative research through in-depth interview with five participants which randomly selected. The questions are open-ended and they can elaborate in many ways. The research question is mainly to discover the awareness of Malaysian people toward PP in local movies.

The total of 6 open-ended questions was asked by researcher through face-to-face interview. The questions are:

1. Are you a fan of Malaysian movies?

2. When was the last time you watch a Malaysian movie?

3. Are you aware of a product placement in Malaysian movies?

4. If yes, what is the title of the movies?

5. Can you tell me what product placement is involved in those movies?

6. Can you mention any products/brand placement involved in these movies?

7. Abang Long Fadil 2 (2017)

8. Ola Bola (2016)

9. J-Revolusi (2016)

10. Polis Evo (2015)

11. Istanbul Aku Datang (2012) 


\section{FINDINGS}

Most of the respondents stated that they are aware and recognize PP in Malaysian movies even most of them are not a fan of Malaysia movies. Other than that, four of them can recall back the brand for specific movie except one participant. Below are some of the statements made by the participants.

\section{Participant 1:}

"I'm not a Malaysian movies fan but I have watched famous Malaysian movies like Abang Long Fadhil 2, Ola Bola and others. I noticed that product placement is being used in movies. In the middle of the movies there will be some time suddenly it focused on the product or logo such as in 'Abang Long Fadil 2' movie. Some of the scenes used product placement of 'Minyak Wakdoyok' in the movie."

\section{Participant 2:}

"I will only watch Malaysian movies when it has a good feedback and very good rating on that movie, usually most of it is box office movies. While I'm watching I will recognize that product or logo if I know the brand. If I don't know the brand maybe I'm not aware of it"

\section{Participant 3:}

"No, I'm not really a fan of Malaysian movies and the last time I watch Malaysian movies at the cinema when I was 17 years old and the movie is 'Ombak Rindu'. I remember one of the product placements in 'Istanbul Aku Datang' is Maggie product. The product appears and the actor dialogue also mentions the name of Maggie 'Asam Laksa' frequently. By the way, I watch that movie because my friends suggest to me that movie and watch it online streaming."

\section{Participant 4:}

"Yes, I like to watch Malaysian movies and also Malaysian drama. The latest movie that I have watched was 'KL Special Force'. The car scene most of it use 'Proton' car and the only car I remembered was 'Ferrari'.

\section{Participant 5:}

"I rarely watch Malaysian movies because most of the Malaysian movies are not best enough. I have watched several Malaysian movies accidentally and I am aware that product placement has been used but I cannot recall the brand on those movies."

\section{CONCLUSION}

In conclusion, this research strongly believes that the potential of using PP in Malaysian movies and indirectly reflect their brand awareness. Moreover, the use of PP in Malaysian movies has successfully represented the brand because they can recall back the brand that they saw in the movies. Furthermore, box office movies are also play the important role of PP towards brand recall. This is because box office movies gain more viewers and lead to potential buyers. This platform should become an advantage for advertiser for using PP in movies to establish the brand for the eyes of Malaysian people. 


\section{REFERENCES}

Balasubramanian, S. K. (2006). Audiene Response to Product Placement. Journal of Advertising, 35(3). $115-141$.

Balasubramanian, S.K (1994). Beyond Advertising and Publicity: Hybrid Messages and Public Policy Issues. Journal of Advertising, 23(4), 29-46.

Cowley, E. \& Barron (2008). 'When product placement goes wrong'. Journal of Advertising, 37,1, 8998.

E. Bressoud, J. M. (2010). The product well placed: The relative impact of placement and audience characteristics on placement recall. Journal of Advertising Research, vol.50,no.4,pp.374-385.

FINAS (2018). Retrieved from FINAS website: http://www.finas.gov.my/en/malaysian-box-office/

Gould, S. J. (2000). Product Placement In Movies: A Cross Cultural Analysis of Austrian, French and American Consumer's Attitudes Toward This Emerging, International Promotional Medium. Journal of Advertising, XXIX (4),41-58.

Homer (2009). Product Placements: The Impact of Placement Type and Repetition on Attitude. Journal of Advertising, 21-31.

Janiszewski,C., Noel, H.\& Sawyer,A.G. (2003). A Meta-analysis of the Spacing Effect in Verbal Learning: Implications for Research on Advertising Repetition and Consumer Memory. Journal of Consumer, 138-149.

Lehu, J. \& Bressoud, E. (2009). Recall of Brand Placement in Movies: Interactions between Prominence and Plot Connection in Real Conditions of Exposure.

Macdonald, E.K. \& B.M. Sharp. (2000). Brand awareness effects on consumer decision making for a common, repeat purchase product: A replication. Journal of Business Research, 48(1), 5-15.

Mandal, M. (. (2008). Brand Placement as Media Vehicle: A study of mainstream film. Indian Instittue of Mass Communication.

Mandler, \&. G. (1980). Recognizing: The Judgment of Previous Occurrence.

MCMC. (n.d.). The Malaysian Communications And Multimedia Content Code. Retrieved from MCMC: https://www.mcmc.gov.my/skmmgovmy/files/attachments/ContentCo de.pdf

Penchmahn, C. (1999). Smoking scenes in movies and antismoking advertisements before movies: Effects on youth. The Journal of Marketing, 1-13.

Psychological Review, 87(3),252-271.

Sung, F. G (2010). Understanding Attitudes Toward and Behaviors In Response to Product Placement. Journal of Advertising, vol.39, no.1,pp. 83-96.

Tessitore, T. (2013). PP for 'Product Placement' or 'Puzzled Public'?". International Journal of Advertising, 32,3,pp.419-442. 